METALLURGY AND FOUNDRY ENGINEERING - Vol. 36, 2010, No. 1

Monika Kuźnia*

\title{
THE INFLUENCE OF TEMPERATURE AND THE RATIO OF AIR EXCESS ON COMBUSTION EFFICIENCY OF POLYOLEFIN MATERIALS
}

\section{INTRODUCTION}

Plastics are becoming more widely used in many areas of the economy. It results in a constant increase in the quantity of waste plastics, in particular of polyolefins, which constitute almost half of all the produced plastics. Main polyolefins include: low and high density polyethylene and polypropylene. One method of disposing of waste plastics is their thermal degradation in waste incinerators or during the blast-furnace process (as a substitute for coke). As it is well known, plastics usually burn rapidly and produce large quantities of carbon black (which is manifested by smoky flame). It is related to the diffusive combustion of plastics. Combustion's products of plastics contain also, in addition to carbon black particles, unreacted reagents.

The aim of this study is to analyze the influence of temperature and the ratio of air excess on the concentration of $\mathrm{CO}$ and $\mathrm{C}_{\mathrm{x}} \mathrm{H}_{\mathrm{y}}$ in waste gases. Series of thermal analyses were carried out before designing the bench. The results and the analysis of these tests enabled us to design the precombustion chamber, the purpose of which is to increase the combustion efficiency.

\section{CHARACTERISTICS OF THE COMBUSTED POLYOLEFIN MATERIALS}

\subsection{Elemental analysis}

The following listed granular polyolefin materials were used in tests: low-density polyethylene (PE-LD), high-density polyethylene (PE-HD) and polypropylene (PP). The elemental analysis of the tested materials has been presented in Table 1.

* Ph.D.: Faculty of Metals Engineering and Industrial Computer Sciences, AGH - University of Science and Technology, Krakow, Poland; e-mail: kuznia@agh.edu.pl 
Table 1. Elemental analysis of polyolefine materials

\begin{tabular}{||c|c|c|c||}
\hline Chemical analysis & PE-LD & PE-HD & PP \\
\hline Elementary analysis (wt.\%): & & & \\
$\mathrm{H}$ & 14.93 & 15.10 & 15.26 \\
$\mathrm{C}$ & 82.80 & 83.00 & 83.10 \\
$\mathrm{~N}$ & 0.07 & 0.10 & 0.03 \\
1.93 & 1.21 & 1.46 \\
\hline Ash.wt.\% & 0.01 & 0.7 & 0.06 \\
\hline Heating value. $\mathrm{MJ} / \mathrm{kg}$ & 42.23 & 42.78 & 43.34 \\
\hline
\end{tabular}

Low calorific value of polyolefin waste (about $43 \mathrm{MJ} / \mathrm{kg}$ ) and its chemical composition (15\% of $\mathrm{H}, 83 \%$ of $\mathrm{C}$ ) makes it a valuable fuel. Very low sulfur content (not exceeding $0,1 \%$ ) is also an important fact resulting in trace (practically zero) concentrations of sulfur dioxide produced in the process of its combustion. Very small quantity of ash $(0,01-0,7 \%)$ remaining after the combustion results in the fact there is no problem with the utilization of combustion residues. In addition, polyolefin wastes constitute combustible substances, which do not create problems during the ignition and combustion. They do not constitute self-extinguishing materials, thus once ignited, they burn until the end.

\subsection{Thermal analysis of the tested materials}

Numerous conclusions may be drawn from author's studies on thermal analysis of the selected plastics $[1,2]$. These observations have been widely described in the previously published materials [1-6]. Numerous methods of thermal analysis have been used, e.g. $T G$, $T G-M S$ or $D S C$. A short analysis of thermal decomposition of plastics has been presented below.

Thermal decomposition of the tested polyolefin materials starts at the temperature amounting to about $250{ }^{\circ} \mathrm{C}$ and ends at about $550{ }^{\circ} \mathrm{C}$, except for the temperature of the end of polypropylene decomposition which amounts to about $400{ }^{\circ} \mathrm{C}$. This may be caused by the fact that polyethylene and polypropylene are made of two different monomers, and thus they differ in terms of their degradation mechanisms. Among all the analyzed waste, highdensity polyethylene is characterized by the highest melting heat, that is about $154 \mathrm{~J} / \mathrm{g}$. Melting heat of materials made of low-density polyethylene amounts to $65-85 \mathrm{~J} / \mathrm{g}$, whilst in the case of polypropylene - about $68 \mathrm{~J} / \mathrm{g}$. These differences can be explained on the basis of the composition of the aforementioned polymers. PE-HD is composed of densely packed, little forked chains, whilst PE-LD possesses forked chains at a greater distance from each 
other. As a result of the formation of dispersive forces, large attraction forces occur between large macromolecules. However, intermolecular attraction forces rapidly decrease as macromolecules move away from each other. As a result of thermal analysis (TG-MS), information on products which, despite the oxidizing environment, did not burn, has been obtained. Among them methane, carbon monoxide, ethylene, formaldehyde, propane, acetaldehyde, propylene, propyne, butane, 1-butene, 1,3-butadiene, benzene, etc. have been identified. Given the self-ignition temperature of the aforementioned substances, it can be concluded that a too low temperature and a too short time spent by those substances in the combustion reactor was the reason why flammable substances remained in waste gases. Interpretation of the results of the conducted thermal analysis enabled us to properly design the precombustion chamber of the furnace, thanks to which the combustion path became longer. Additionally, the process was conducted at high temperatures, allowing materials produced in the process of thermal degradation to burn to the end.

\section{THE APPARATUS}

Figure 1 presents the diagram of laboratory set and its photo has been given at the Figure 2. Precombustion chamber shown in Figure 3 is composed of a pipe, which supplies air and the chamber in the form of a cylinder with a permanently fixed grate in the form of a metal plate with drilled holes with diameter of about $2 \mathrm{~mm}$. Half of the air was supplied above the grate, and half under the grate. Precombustion chamber is used for thermal decomposition of thermoplastics. Phenomena, which take place in it, include: melting, pyrolysis and combustion of combustible materials.

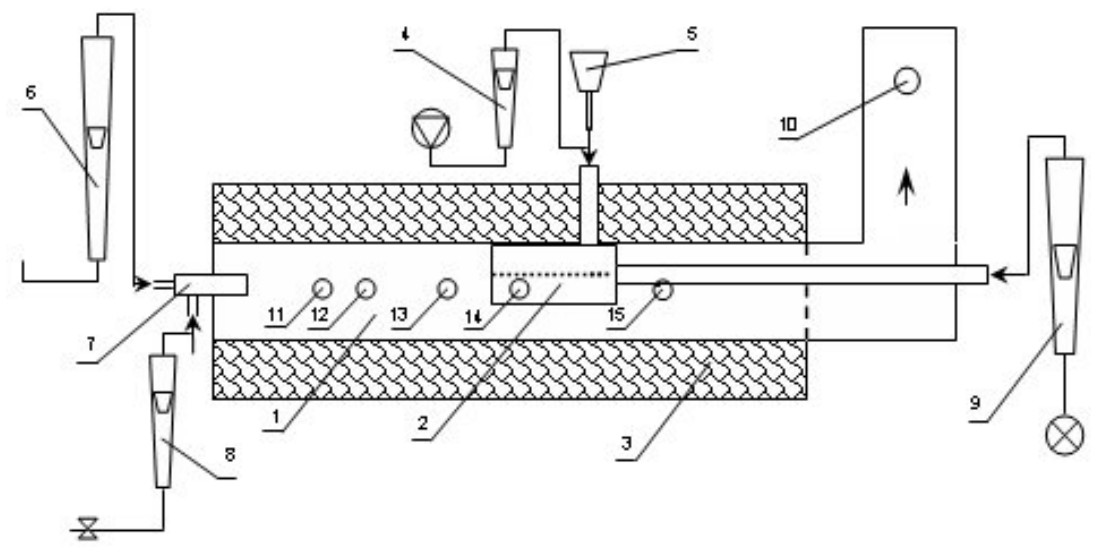

Fig. 1. Diagram of laboratory set: 1 - combustion chamber; 2 - precombustion chamber; 3 - thermal insulation; 4, 6, 9 -air rotameters; 5 - granulate feeder; 7 - kinetic burner; 8 -gas rotameter; 10 - place of exhaust gas collection; 11, 12, 13, 14, 15 - sight glasses, temperature measurement points 


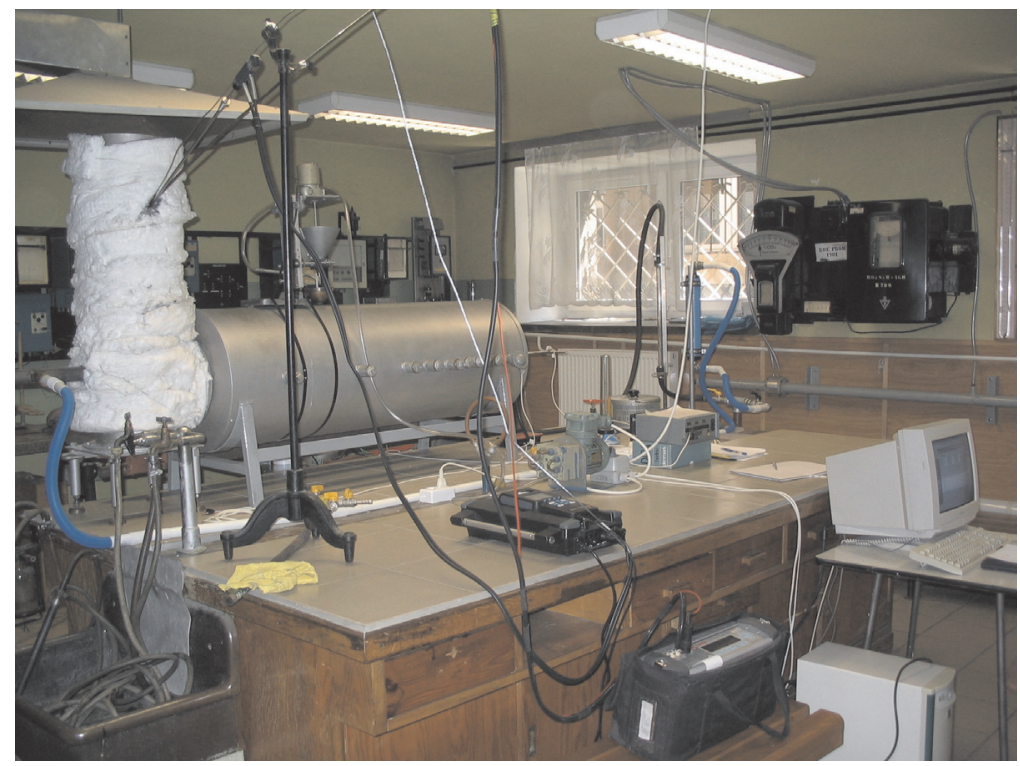

Fig. 2. Photo of laboratory set

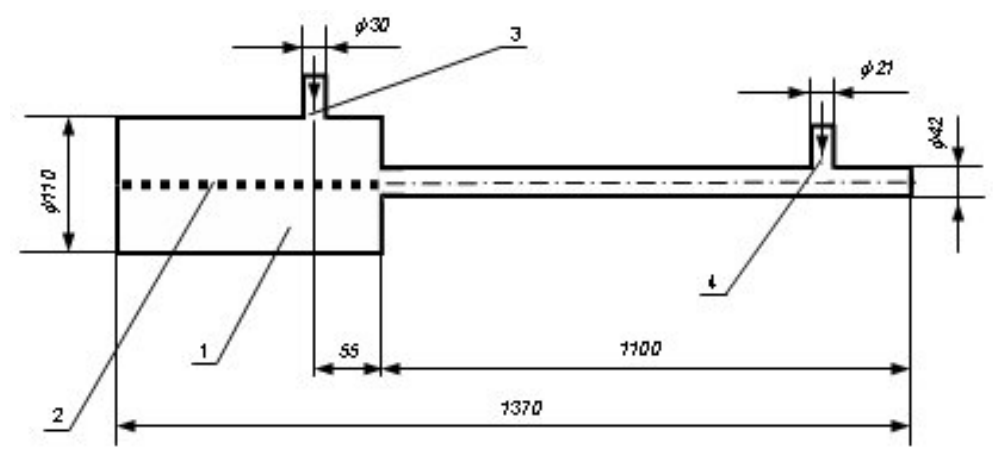

Fig. 3. Precombustion chamber: 1 - before-combustion chamber, 2 - grate, 3 - place of granulate supply, 4 - place of supplying air for combustion

During the thermal degradation of polymer chains, the recombination of fragments of chains as well as generation of new compounds, often with a complex structure, including $\mathrm{PAH}$, take place as well. Therefore, it is very important to extend the combustion path in order to burn the produced flammable compounds to the end. Combustion chambers shall perform such a task. A mixture of flammable and partially burned compounds gets out of precombustion chamber and then flows into the combustion chamber. Here, the specific combustion and reversal of the direction of exhaust flow take place. Change in the direction creates turbulences in the combustion chamber, and this undoubtedly influences the com- 


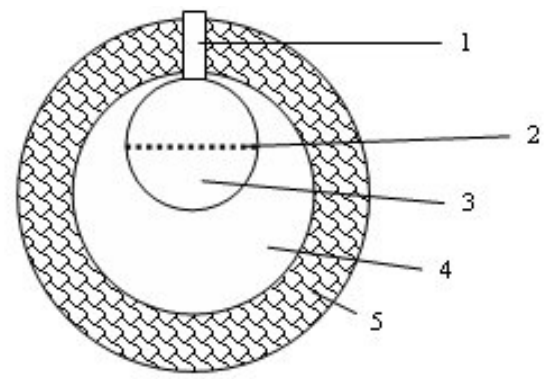

Fig. 4. Cross section of the furnace: 1 -place of granulate supply, 2 - grate, 3 - precombustion chamber, 4 - combustion chamber, ;6- thermal insulation bustion process. Turbulent mixing of oxidizer and fuel increases the combustion speed of combustible mixture. Flue gases move from the combustion chamber towards the stack, flowing under the precombustion chamber. The precombustion chamber has been placed in such a way that the majority of exhaust gases flow under it. This improves the heat transfer between the exhaust gases and the precombustion chamber. In the final stage of the path, flowing gases heat the pipe, which supplies air and then flow into the stack. Cross section of the furnace is shown in Figure 4.

\section{METHODOLOGY OF TESTS}

Measurements were carried out as follows:

1. The furnace was heated to the planned temperature with the use of natural gas burned in a kinetic burner.

2. After heating the furnace to the planned temperature, gas supply was cut off by closing the gas valve.

3. Next, with the use of a screw feeder, granulate was supplied to the furnace precombustion chamber.

4. Air was supplied to the combustion chamber at three points:

- to the precombustion chamber with the use of a pipeline. Air flowrate constituted a major amount of combustion air, controlled with the use of a valve.

- through the kinetic burner, the volume of air flowing through the kinetic burner was reduced to $1 \mathrm{~m}^{3} / \mathrm{h}$, for all measurements. The air cooled the burner and thus protected it against destruction. Whilst flowing out in the direction contrary to products flowing from the precombustion chamber, it increased turbulence (mixing), thus speeding up the combustion rate.

- from the top, through the opening used in order to supply granulate, in the amount of $0.7 \mathrm{~m}^{3} / \mathrm{h}$ in order to prevent possible leakage of gaseous products of degradation from the precombustion chamber.

5. Measurements were started after obtaining stable parameters of the media flow and were carried out until the temperature began to drop below the assumed temperature range.

In the case of PE-HD, measurements at the temperature amounting to $1150{ }^{\circ} \mathrm{C}$ were not carried out because the process of melting PE-HD was starting in the feeder which made it impossible to supply the granulate regularly. In turn, during the combustion of PE-LD at temperatures lower than $1100{ }^{\circ} \mathrm{C}$, visible amounts of carbon black were produced; therefore the measurements were abandoned when the temperature dropped below $1100{ }^{\circ} \mathrm{C}$. 
Temperature measurements. Measurements of temperature along the combustion chamber were carried out with the use of five $\mathrm{NiCr}-\mathrm{NiAl}$ thermocouples connected to a data acquisition system. The measuring step was set to 10 seconds.

Measurement of concentrations of combustion products. Concentrations of combustion products were measured the axis of the flue gases stack. Two exhaust gases analyzers were used:

- TESTO $350 \mathrm{XL}$ for the purposes of measuring the concentrations of: $\mathrm{O}_{2}, \mathrm{CO}, \mathrm{NO}$, $\mathrm{NO}_{2}, \mathrm{SO}_{2}, \mathrm{C}_{\mathrm{x}} \mathrm{H}_{\mathrm{y}}$ and the temperature of exhaust gases in the place of their collection. In order to register data, testo easyEmission Software Version 1.4 was used. The measuring step was set to 10 seconds,

- LAND LANCOM II in order to measure the concentrations of $\mathrm{CO}_{2}$ and $\mathrm{C}_{\mathrm{x}} \mathrm{H}_{\mathrm{y}}$ on a confirmation basis.

\section{RESULTS AND DISCUSSION}

The temperature constitutes one of the most important parameters of combustion process as it significantly affects the process rate, effectiveness of $\mathrm{CO}$ afterburning, emission of volatile pollutants. Charts presented below illustrate the dependence of the concentrations of $\mathrm{CO}$ and $\mathrm{C}_{\mathrm{x}} \mathrm{H}_{\mathrm{y}}$ on air excess in certain temperature ranges.

Combustion of PE-LD in the temperature amounting to $1150{ }^{\circ} \mathrm{C}$ is most efficient at $\lambda=1.53$ (Fig. 5a) whilst PP at $\lambda=1.43 \div 1.53$ (Fig. 5b). Different degree of granularity of the combusted materials and more specifically greater diameter of PE-LD granulate might have influenced the slightly increased demand for combustion air. The increase in concentration of pollutions, despite a further increase in excess air ratio, may be caused by the presence of microareas of lower temperatures in which complete oxidation does not takes place as well as by the "shift" of the combustion area. Combustion of PE-HD (Fig. 5c) and PP (Fig. 6a) at the temperature amounting to $1000{ }^{\circ} \mathrm{C}$ is more effective at $\lambda=1.53$. However, the concentrations of $\mathrm{CO}$ and $\mathrm{C}_{\mathrm{x}} \mathrm{H}_{\mathrm{y}}$ (as methane) are higher than the concentrations occurring during the combustion of PE-LD and PP at the temperature of $1150{ }^{\circ} \mathrm{C}$. During the combustion of PE-HD (Fig. 6b) and PP (Fig. 6c) at the temperature amounting to about $900{ }^{\circ} \mathrm{C}$, the lowest concentrations occurred at $\lambda=1.53 \div 1.63$. Nevertheless, the aforementioned concentrations are at the same time the highest among the lowest ranges of concentrations for the presented temperature ranges.

On the basis of the test results, one may clearly see the influence of the combustion temperature and the ratio of excess air on the volume of pollutants concentration in flue gases. The lowest concentrations occur at the temperature of $1150{ }^{\circ} \mathrm{C}$, at the range $\lambda=1.43 \div 1.53$. High temperature increases the combustion rate as a greater quantity of radicals is formed at high temperatures. The combustion efficiency detoriates as the temperature decreases and as the ratio of excess air increases above $\lambda=1.63$. 
a)

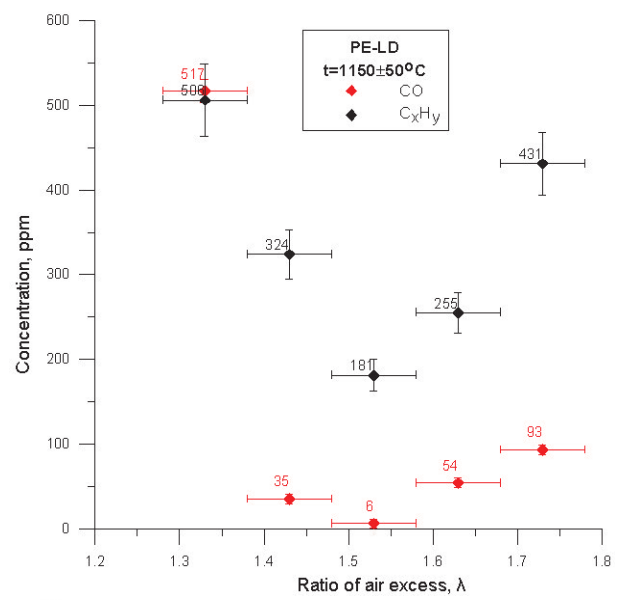

b)

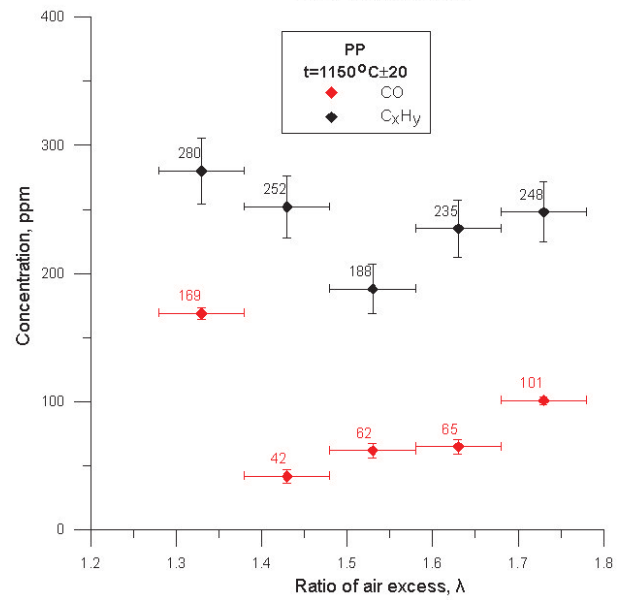

c)

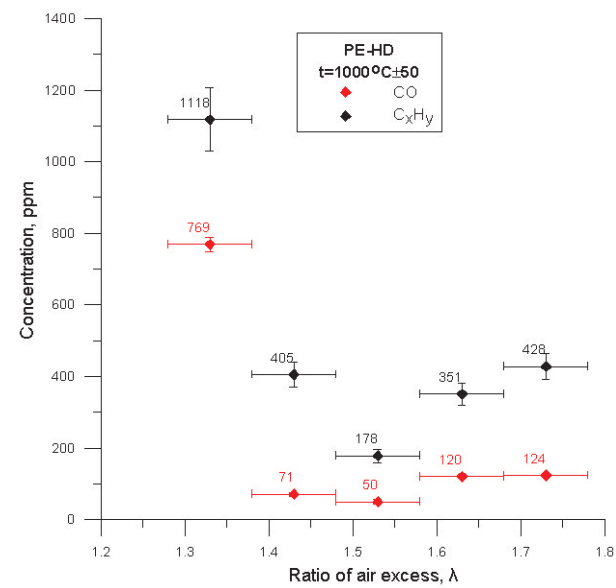

Fig. 5. Concentrations of $\mathrm{CO}$ and $\mathrm{C}_{x} \mathrm{H}_{y}$ in flue gases produced during the combustion at the temperature amounting to: a) $1150 \pm 50{ }^{\circ} \mathrm{C}(P E-L D)$, b) $1150 \pm 50{ }^{\circ} \mathrm{C}(P P)$, c) $1000 \pm 50{ }^{\circ} \mathrm{C}(P E-H D)$ 
a)

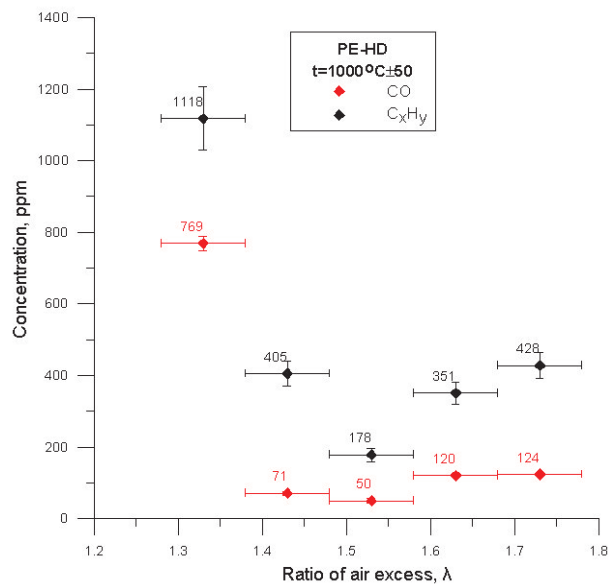

b)

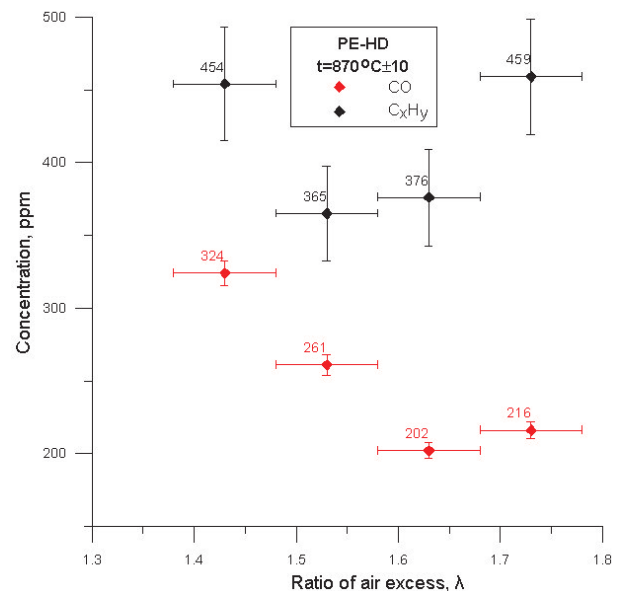

c)

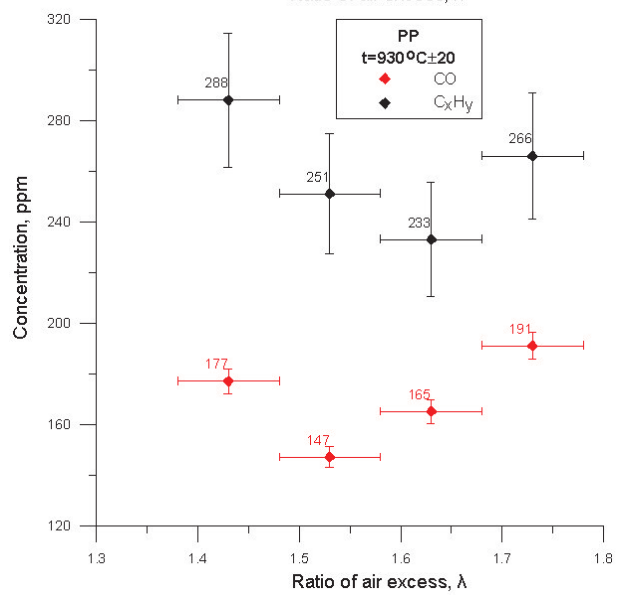

Fig. 6. Concentrations of $\mathrm{CO}$ and $\mathrm{C}_{x} \mathrm{H}_{y}$ in flue gases produced during the combustion at the temperature amounting to: a) $1000 \pm 50{ }^{\circ} \mathrm{C}(P E-H D)$, b) $870 \pm 10{ }^{\circ} \mathrm{C}(P E-H D)$, c) $930 \pm 20{ }^{\circ} \mathrm{C}(P P)$ 
All the analyzed polyolefins (PE-LD, PE-HD, PP) burn in a similar manner. Minimum CO concentration occurs for similar values of the ratio of excess air $\lambda=1.43$ and $\lambda=1.53$ at different combustion temperatures. Minimum CO concentrations of the tested materials fall within the range of 6-45 ppm for the temperature amounting to $1150{ }^{\circ} \mathrm{C}, 50-90 \mathrm{ppm}$ for the temperature amounting to $1000{ }^{\circ} \mathrm{C}$ and $150-202$ for the temperature amounting to $900{ }^{\circ} \mathrm{C}$. The minimum $\mathrm{C}_{\mathrm{x}} \mathrm{H}_{\mathrm{y}}$ concentration at the same air excess values are as follows: $180 \mathrm{ppm}$ for the temperature amounting to $1150{ }^{\circ} \mathrm{C}$, about $160-180$ for the temperature amounting to $1000{ }^{\circ} \mathrm{C}$ and about $230-360$ for the temperature amounting to $900{ }^{\circ} \mathrm{C}$.

\section{CONCLUSIONS}

1. Combustion efficiency has been evaluated on the basis of the $\mathrm{CO}$ and $\mathrm{C}_{\mathrm{x}} \mathrm{H}_{\mathrm{y}}$ (as methane) concentration. The best conditions were obtained at the combustion temperature amounting to $1150{ }^{\circ} \mathrm{C}$ and at the ratio of excess air $\lambda=1,53$. On the basis of the tests carried out at the bench, it may be assumed that the produced combustible substances were completely burned. However, there are no qualitative tests of hydrocarbons and intermediate products depositing on carbon black, which appears in very small quantities, which prevents us to analyze fully the efficiency of the combustion process.

2. Curves drawn on the basis of $\mathrm{CO}$ and $\mathrm{C}_{\mathrm{x}} \mathrm{H}_{\mathrm{y}}$ concentrations (in all temperature ranges) from the ratio of excess air have a parabolic shape. The increase in concentration of pollutants at lower ratios of excess air is caused by a deficiency of the oxidizer, whilst at higher excess of air the "hijacking" of unburned particles from the precombustion chamber takes place.

3. All of the analyzed polyolefins (PE-LD, PE-HD, PP) burn in a similar manner. Minimum $\mathrm{CO}$ and $\mathrm{C}_{\mathrm{x}} \mathrm{H}_{\mathrm{y}}$ concentrations occur in the case of similar values of the ratio of excess air $\lambda=1.43$ and $\lambda=1.53$ at different combustion temperatures. On the basis of the combustion process of the tested polyolefin materials, similar characteristics of the combustion process for the whole group of polyolefins may be expected.

\section{REFERENCES}

[1] Kuźnia M., Magdziarz A.: Thermal degradation of waste polyolefines and their application in blast-furnace process, Metallurgy and Foundry Engineering, 32 (2006) 2, 117-123

[2] Kuźnia M., Magdziarz A.: Thermal recycling of waste polyolefines in heavy industry, ESTAC 9: $9^{\text {th }}$ European Symposium on Thermal Analysis and Calorimetry: 27-31 August 2006, Kraków, Poland: book of abstracts, Wyd. Nauk. „Akapit”, 2006, p. 149

[3] Fink J.K.: Pyrolysis and combustion of polymer wastes in combination with metallurgical processes and the cement industry, Journal of Analytical and Applied Pyrolysis, 51 (1999) 239-252

[4] Wheatley L., Levendis Y.A., Vouros P.: Exploratory Study on the Combustion and PAH Emissions of Selected Municipal Waste Plastics, Environmental Science and Technology, 27 (1993) 2885-2895 
[5] Piao M., Chu A., Zheng M., Xu X.: Characterization of the combustion products of polyethylene, Chemosphere, 39 (1999) 1497-1512

[6] Font R., Aracil I., Fullana A., Conesa J.A.: Semivolatile and volatile compounds in combustion of polyethylene, Chemosphere, 57 (2004) 615-627

Received

June 2010 